\title{
Consumo Foliar de Eucalyptus spp. por Acromyrmex disciger (Mayr) (Hymenoptera: Formicidae)
}

\author{
Wagner Calixto de Castro Morais ${ }^{\bowtie}$, Norivaldo dos Anjos, Terezinha Maria Castro Della Lucia \\ 1. Universidade Federal de Viçosa, e-mail: wagnercalixto@florestal.eng.br (Autor para correspondência ${ }^{\bowtie}$ ), nanjos@ufv.br, tdlucia@ufv.br. \\ EntomoBrasilis 4 (2): 73-74 (2011)
}

Resumo. O potencial produtivo de plantios florestais é reduzido, dentre outros fatores, pela ocorrência de pragas. No Brasil, as formigas-cortadeiras são os principais insetos daninhos à cultura do eucalipto. Dentre as espécies dessas formigas, Acromyrmex disciger (Mayr) se destaca na região Sudeste do Brasil. Entretanto, poucas são as informações a respeito de seu potencial de dano às plantações de eucalipto. Este trabalho teve por objetivo quantificar o consumo foliar de eucalipto por A. disciger, em condições de laboratório. Para isto, folhas frescas de Eucalyptus grandis W. Hill ex Maiden, Eucalyptus urophylla ST Blake e do híbrido E. urophylla x E. grandis foram oferecidas, com chance de escolha, à duas colônias de $A$. disciger, durante 24 horas, num total de oito repetições. O consumo foliar foi determinado pela diferença entre as massas de folhas e de suas

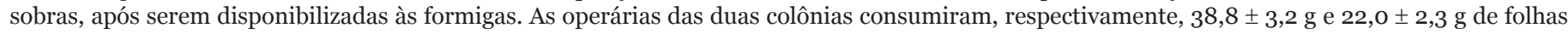
de eucalipto, por dia. Estes elevados valores podem sugerir estado de alerta para os danos que $A$. disciger pode causar nos plantios de eucalipto, merecendo, esta formiga-cortadeira, maior atenção.

Palavras-chave: Entomologia florestal, eucaliptocultura, formiga cortadeira.

\section{Eucalypt leaf-consumption by Acromyrmex disciger (Mayr) (Hymenoptera: Formicidae)}

\begin{abstract}
The productive potential of forest stands is reduced by pest occurrence among other factors. In Brazil, leaf-cutting ants are the most severe eucalypt pests. Acromyrmex disciger (Mayr) is prevalent in the south east Brazil. However, scarce information about its potential damage for Eucalyptus forests is available. This work deals to quantifying the eucalypt leaf-consumption by such specie of leaf-cutting ant. Fresh leaves were taken from trees of Eucalyptus grandis W. Hill ex Maiden, Eucalyptus urophylla ST Blake, and hybrid E. urophylla x E. grandis and served to different colonies of $A$. disciger, during 24 hours period, over eight different times. Leaf-consumption was calculated throughout fresh weights of leaves, before and after ants foraging. Each colony of A. disciger consumed $38.8 \pm 3.2 \mathrm{~g}$ e $22.0 \pm 2.3 \mathrm{~g}$ of eucalypt leaves, per day.
\end{abstract}

Keywords: Eucalypt plantation, forest entomology, leaf-cutting ant.

A área coberta por plantios florestais de eucaliptos no Brasil corresponde a 4.515.730 hectares e a produtividade nacional média é de 40,5 m3 ha-1.ano-1 (ABRAF 2010). Esta produtividade seria maior, não fosse a ocorrência de pragas, que causam danos às plantações, reduzindo seu potencial de produção (Mendes Filho 1981). Dentre essas pragas, as mais importantes, do ponto de vista econômico e pela sua vasta distribuição geográfica, são as formigas cortadeiras (MARICONI 1970; Ansos et al. 2007). As quenquéns, como são conhecidas as formigas cortadeiras do gênero Acromyrmex, apresentam potencial de dano às plantações menor do que o das saúvas (gênero Atta), entretanto, quando a quantidade de ninhos é elevada, elas podem provocar perdas consideráveis em plantios recentes e brotações (Anjos et al. 2007). De acordo com Mendes FILHo (1981), esta perda chega a 30\% das brotações de eucaliptos, num plantio com densidade de 200 quenquenzeiros por hectare. Acromyrmex disciger (Mayr) é uma espécie de quenquém nativa do continente americano (GonÇALVES 1961). No Brasil, a quenquém-mirim, como é popularmente conhecida, ocorre nos estados do Rio Grande do Sul (Diehl \& Albuquerque 2007), Minas Gerais, São Paulo, Rio de Janeiro, Paraná e Santa Catarina, sendo, neste último, a formiga cortadeira mais importante, em locais onde não ocorrem saúvas (GonÇALVES 1961).

O consumo foliar de formigas-cortadeiras do gênero Acromyrmex já foi avaliado para as espécies Acromyrmex subterraneus subterraneus Forel, de acordo com PEREIRA (1995), e Acromyrmex laticeps nigrosetosus Forel, conforme ANTUNES \& Della Lucia (1999); Marsaro Júnior et al. (2007), entretanto, não há informações deste consumo para $A$. disciger, sendo desconhecidas, também, as perdas que esta formiga pode causar na cultura do eucalipto.

Portanto, este trabalho teve por objetivo quantificar o consumo foliar por colônias $A$. disciger em eucaliptos, sob condições de laboratório.

O trabalho foi realizado no Insetário do Departamento de Biologia Animal da Universidade Federal de Viçosa (UFV), em Viçosa, Minas Gerais, nos meses de maio e junho de 2008, tendo sido utilizadas duas colônias de $A$. disciger, disponíveis, de tamanhos e idades semelhantes e, mantidas sob condições de laboratório, conforme recomendadas por DelLa Lucia et al. (1993). Utilizou-se o delineamento experimental inteiramente casualizado.

Folhas tenras e frescas de Eucalyptus grandis W. Hill ex Maiden, Eucalyptus urophylla ST Blake e do híbrido 
E. urophylla x E. grandis, foram oferecidas, com chance de escolha e em quantidades semelhantes, às colônias da referida formiga-cortadeira, por um período de 24 horas, repetidamente em oito avaliações. As folhas foram pesadas imediatamente antes de serem servidas às formigas e as sobras foram pesadas ao final de cada período de forrageamento. A massa das sobras foi corrigida com base na variação da massa de folhas deixadas como testemunhas, no mesmo ambiente das avaliações de forrageamento, conforme preconizaram ANTUNES \& DELLA LuCIA (1999). Para evitar o condicionamento das formigas ao substrato à base de eucaliptos, foram oferecidas folhas de Alfeneiro (Ligustrum japonicum Thunb.) (Oleaceae) e Acalifa (Acalypha wilkesiana Muell. Arg.) (Euphorbiaceae) durante igual período de 24horas, entre as avaliações.

Os consumos de folhas não apresentaram diferença significativa entre si (Tabela 1), indicando que não houve preferência de $A$. disciger entre as espécies de eucalipto avaliadas. Este resultado foi semelhante ao encontrado por MARSARO JÚNIOR et al. (2007), que investigaram a preferência de corte da quenquém A. laticeps nigrosetosus em Eucalyptus spp., e concluíram que folhas de $E$. urophylla e de um híbrido de $E$. grandis foram igualmente aceitas pela formiga.

Tabela 1. Consumos diários médios $(\mathrm{n}=8)$, em gramas, de folhas de eucaliptos, por Acromyrmex disciger Mayr. Letras iguais correspondem, estatisticamente, a médias equivalentes, pelo Teste t $(\mathrm{P} \leq 0,05)$. Letras minúsculas comparam os consumos para as espécies de Eucalyptus, enquanto maiúsculas comparam os consumos diários totais. Viçosa-MG. 2008.

\begin{tabular}{|c|c|c|c|c|c|}
\hline \multirow{2}{*}{ Colônia } & & \multicolumn{4}{|c|}{ Consumo (gramas) } \\
\hline & & $\underset{\text { grandis }}{E .}$ & $\begin{array}{c}E . \\
\text { urophylla }\end{array}$ & Híbrido & Total \\
\hline \multirow{3}{*}{ A } & Média & 12,2 a & 13,5 a & 13,1 a & 38,8 A \\
\hline & $\begin{array}{l}\text { Erro- } \\
\text { padrão }\end{array}$ & 0,9 & 2,1 & 1,5 & 3,2 \\
\hline & $\mathrm{CV}$ & $21 \%$ & $43 \%$ & $32 \%$ & $24 \%$ \\
\hline \multirow{3}{*}{ B } & Média & $6,3 \mathrm{~b}$ & $9,7 \mathrm{~b}$ & $6,0 \mathrm{~b}$ & 22, 0 B \\
\hline & $\begin{array}{l}\text { Erro- } \\
\text { padrão }\end{array}$ & 1,1 & 2,2 & 1,0 & 2,3 \\
\hline & $\mathrm{CV}$ & $48 \%$ & $65 \%$ & $48 \%$ & $30 \%$ \\
\hline
\end{tabular}

Os consumos diários de folhas de eucalipto, obtidos através das médias de consumo total para cada colônia, foram de $38,8 \pm 3,2$ g e 22,0 $\pm 2,3$ g, para as colônias A e B, respectivamente. Estes valores parecem ser muito superiores aos 3,53 g diários encontrados por Antunes \& Della Lucia (1999) para A. laticeps nigrosetosus, entretanto, o consumo médio da colônia $\mathrm{B}$ pode ser semelhante ao consumo diário de $18 \mathrm{~g}$ para A. subterraneus subterraneus, conforme relatado por PEREIRA (1995).

Considerando que uma muda de qualidade padrão tem três pares de folhas e que uma folha tem, aproximadamente, o,4 gramas, uma colônia de $A$. disiciger, seria capaz de desfolhar diariamente de 9 a 16 mudas. Em um plantio florestal com grande densidade de colônias, como os 147 ninhos de Acromyrmex crassispinus Forel por hectare, encontrados por UKAN (2008), o desfolhamento por $A$. disciger poderia atingir $100 \%$ das mudas de eucalipto.

\section{Como citar este artigo:}

Morais, W.C.C., N. Anjos \& T.M.C. Della-Lucia, 2011. Consumo Foliar de Eucalyptus spp. por Acromyrmex disciger (Mayr, 1887) (Hymenoptera: Formicidae). EntomoBrasilis, 4(2): 73-74. www.periodico.ebras.bio.br/ojs
Estas inferências podem sugerir estado de alerta para os danos que $A$. disciger pode causar nos plantios de eucalipto, merecendo, esta formiga-cortadeira, maior atenção.

\section{REFERÊNCIAS}

Associação Brasileira de Produtores de Florestas Plantadas. 2010. Anuário estatístico da ABRAF: ano base 2009 / ABRAF. Brasília. 140p. Disponível em: <http://www.abraflor.org.br/estatisticas/ABRAF10-BR. pdf> [12/05/2010].

Anjos, N., T.M.C. Della Lucia \& A.J. Mayhé-Nunes, 2007. Guia prático sobre formigas cortadeiras em reflorestamentos. 2 ed. Ponte Nova: Graff cor, 97p.

Antunes, E.C. \& T.M.C. Della Lucia, 1999. Consumo foliar em Eucalyptus urophylla por Acromyrmex laticeps nigrosetosus Forel (Hymenoptera: Formicidae). Ciência e Agrotecnologia, 23: 208-211.

Della Lucia, T.M.C., E.F. Vilela, N. Anjos \& D.D.O. Moreira, 1993. Criação de formigas cortadeiras em laboratório. In: Della Lucia, T.M.C. (ed). As formigas cortadeiras. Viçosa, UFV, 262p.

Diehl, E. \& E.Z. Albuquerque, 2007. Representantes das quatro províncias geomorfológicas do Rio Grande do Sul na coleção de Formicidae do Laboratório de Insetos Sociais da Unisinos. Biológico, São Paulo, 69: 101-104.

Gonçalves, C.R., 1961. O Gênero Acromyrmex no Brasil (Hymenoptera: Formicidae). Studia Entomológica, 4: 113180.

Mariconi, F.A.M., 1970. As saúvas. São Paulo, Ed. Agronômica Ceres, 167p.

Marsaro Júnior, A.L., A.J. Molina-Rugama, C.A. Lima \& T.M.C. Della Lucia, 2007. Preferência de corte de Eucalyptus spp. por Acromyrmex laticeps nigrosetosus Forel, 1908 (Hymenoptera: Formicidae) em condições de laboratório. Ciência Florestal, 17: 171-174.

Mendes Filho, J.M.A., 1981. Ação danosa de pragas desfolhadoras sobre as florestas de Eucalyptus. IPEF. Circular Técnica n. 131.

Pereira, R.C., 1995. Estimativa de consumo foliar por Atta sexdens rubropilosa Forel, 1908 e Acromyrmex subterraneus subterraneus Forel, 1893 (Hymenoptera: Formicidae) em povoamentos de eucalipto na Cenibra Florestal S.A. In: Paiva, H.N. (Editor). Trabalhos monográficos dos estudantes de Engenharia Florestal - Julho de 1995. Viçosa. UFV. 159p.

Ukan, D., 2008. Avaliação qualitativa e quantitativa de microporta-iscas para o controle de formigas-cortadeiras em plantios de Eucalyptus urograndis submetidos a diferentes cronogramas silviculturais. 2008. Dissertação (Mestrado em Ciência Florestal). Universidade Federal do Paraná. 78p.

Recebido em: 23/04/2010

Aceito em: 06/09/2010

$* * * * * * * * * * * * *$
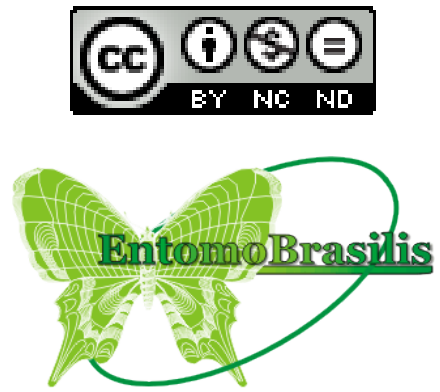